\title{
Maxillo-Mandibular Cemento-ossifying Fibroma: A Rare Case Report
}

\author{
Ranjit Kumar Peravali • H. Hari Kishore Bhat • \\ Sreenatha Reddy
}

Received: 22 July 2012/ Accepted: 20 March 2013/Published online: 2 April 2013

(C) Association of Oral and Maxillofacial Surgeons of India 2013

\begin{abstract}
Cemento-ossifying fibroma (COF) is a benign fibro osseous lesion of the jaws which has been described as a demarcated or rarely encapsulated neoplasm consisting of fibrous tissue and varying amounts of mineralized material resembling bone and/or cementum (Dinkar et al. in IJDA 2(4):45-47, 2010). Majority of lesions occur in the mandible and only few cases of COFs of the maxillary sinus and bilateral COFs of the mandible have been reported in literature (Dinkar et al. in IJDA 2(4):45-47, 2010; Tamiolakis et al. in Acta Stomatol Croat 39(3):319-321, 2005; Hamner et al. in Oral Surg Oral Med Oral Pathol 26(4):579-587, 1968; Gunaseelan et al. in Oral Med Oral Pathol Oral
\end{abstract}

R. K. Peravali · H. H. K. Bhat · S. Reddy

Department of Oral and Maxillofacial Surgery, Sri Sai College of Dental Surgery, Opp. Shiv Sagar, Kotherapally, Vikarabad, Andhra Pradesh, India

e-mail: dsr3636@yahoo.com

Present Address:

H. H. K. Bhat ( $\square)$

Department of Oral and Maxillofacial Surgery, Centre for Craniofacial Anomalies, Yenepoya Dental College and Hospital, Yenepoya University Campus, Nithyananda Nagar, Deralakatte, Mangalore 575018, Karnataka, India e-mail: harimaxfac@gmail.com; haridentist@yahoo.co.in
Radiol Endod 104:e21-e25, 2007). These lesions have a very low recurrence rate (Ertug et al. in Quintessence Int 35(10):808-810, 2004) and are generally treated by enucleation. In this paper we present a rare case of COF occurring in both the maxilla and mandible of the same patient. Only one such case (Takeda and Fujioka in Int J Oral Maxillofac Surg 16(3):368-371, 1987) has been reported in literature so far.

Keywords Cemento-ossifying fibroma $\cdot$ Bi-jaw · Maxilla-mandibular

\section{Introduction}

Cemento-ossifying fibroma (COF) is a unique benign fibro osseous lesion of the jaws characteristically containing fibrous tissue, varying amounts of calcified tissue resembling bone, cementum, or both and a capsule [1,7-9]. COF is a slow growing tumour causing enlargement of the affected bone and is most often discovered incidentally $[7,10]$.

Cemento-ossifying fibroma has a definite female predilection with female-to-male ratio as high as 5:1 [2, 5, 8, 11-13]. Most of these slow-growing asymptomatic, intraosseous masses are diagnosed between 20 and 40 years of age even though they can occur in a wider age range (2nd6th decade) $[2,5,12,13]$.

In $62-89 \%$ of patients COF affects the mandible with a marked percentage involving premolar-molar region $[1,8$, 10-14]. Although the mandible is more commonly affected than the maxilla, few cases of COFs of the maxillary sinus and bilateral COFs of the mandible have been reported in literature [1-4]. 
We present a rare case of COF that involved both maxilla and mandible in the same patient. Only one such case [6] has been reported in literature so far. We report this case because of its rarity and scarceness of information regarding such lesions in the oral and maxillofacial literature.

\section{Case Report}

A 47 year old male patient reported to the department of oral and maxillofacial surgery with a complaint of painless swelling in the right lower jaw since 3 years. Following trauma to the same region 3 years ago, a peanut size swelling developed, which gradually increased to the present size.

On examination, extra orally a well-defined swelling in the right body of mandible was noticed causing severe facial asymmetry (Fig. 1a). The swelling approximately measured $7 \mathrm{~cm} \times 5 \mathrm{~cm}$, was bony hard in consistency and nontender. Skin over the swelling was normal in colour and texture and was pinchable. There was an evidence of paresthesia over the right lip region. The lymph nodes were not palpable. Intra-orally, there was significant buccolingual cortical expansions extending from lower right lateral incisor to the second molar region with intact overlying mucosa. Buccal vestibule was obliterated and the swelling was bony hard in consistency (Fig. 1a). There was no pus/ blood discharge. The teeth in the fourth quadrant were lingually displaced, deranging the occlusion. The lower right premolars and first molar were mobile and non-vital. Incidentally during extra oral examination a diffuse swelling, about which the patient was unaware, was noticed over the left maxillary region obliterating the left naso-labial fold. Intra-orally there was expansion of left anterior wall of the maxillary sinus obliterating the buccal vestibule.

OPG revealed a well-defined radiolucent lesion with sclerotic margins measuring approximately $7 \mathrm{~cm} \times 5 \mathrm{~cm}$ extending from lower right canine to distal surface of second molar tooth region anteroposteriorly. Inferior border of mandible was thinned out but intact. There was evidence of superior displacement of lower right canine, premolars and first molar with resorption of mesial root of
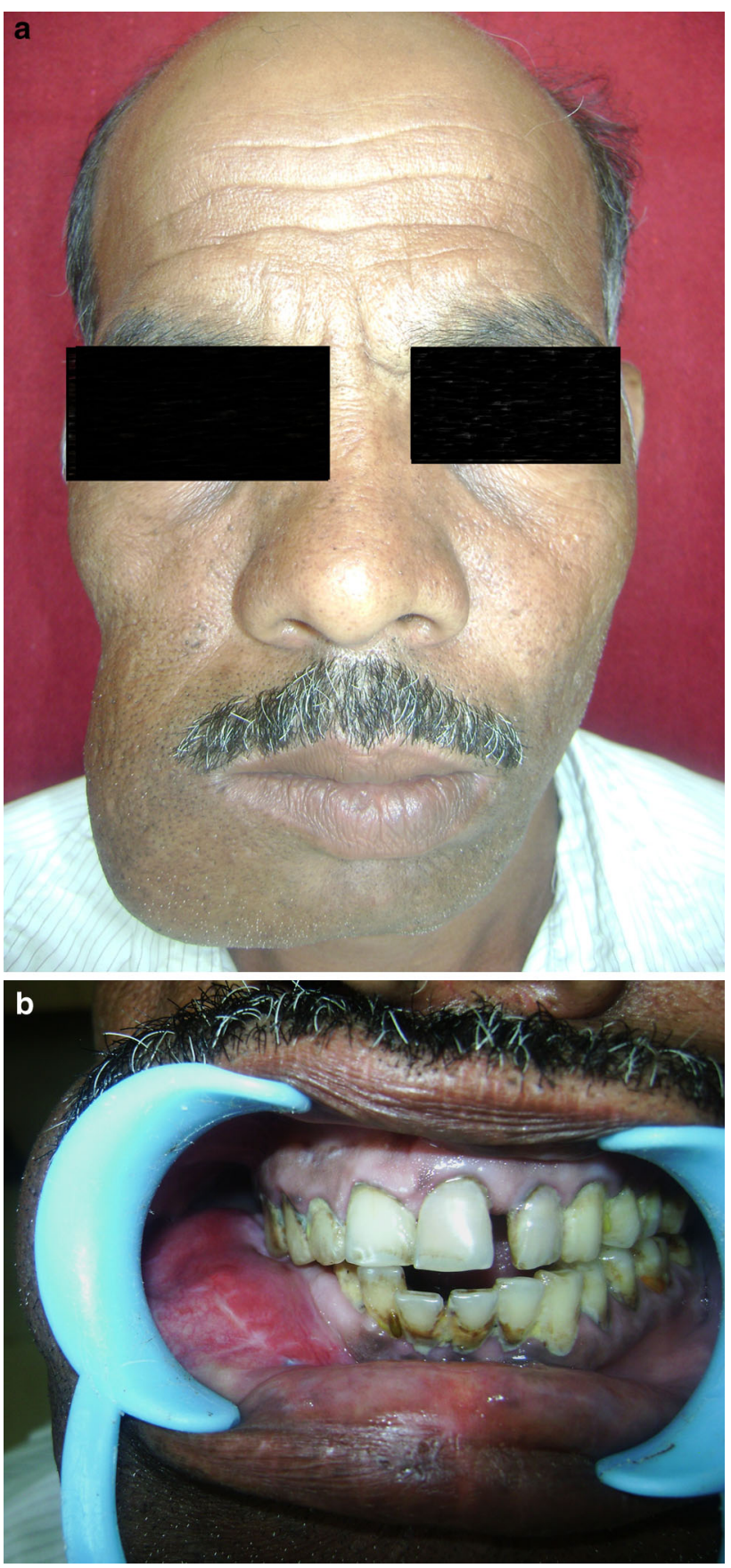

Fig. 1 a Marked facial asymmetry seen with a diffuse swelling in the right body of the mandible region. b Bucco-lingual cortical expansion causing vestibular obliteration, extending from 42 to 47 with intact overlying mucosa. The teeth were lingually displaced, deranging the occlusion 
Fig. 2 a OPG showing a welldefined radiolucency with sclerotic margins extending from lower right canine to distal surface of second molar.

Thinning out of the lower border of mandible and displacement of teeth is evident. b CT axial section showing a hyperdense lesion within the left maxillary antrum
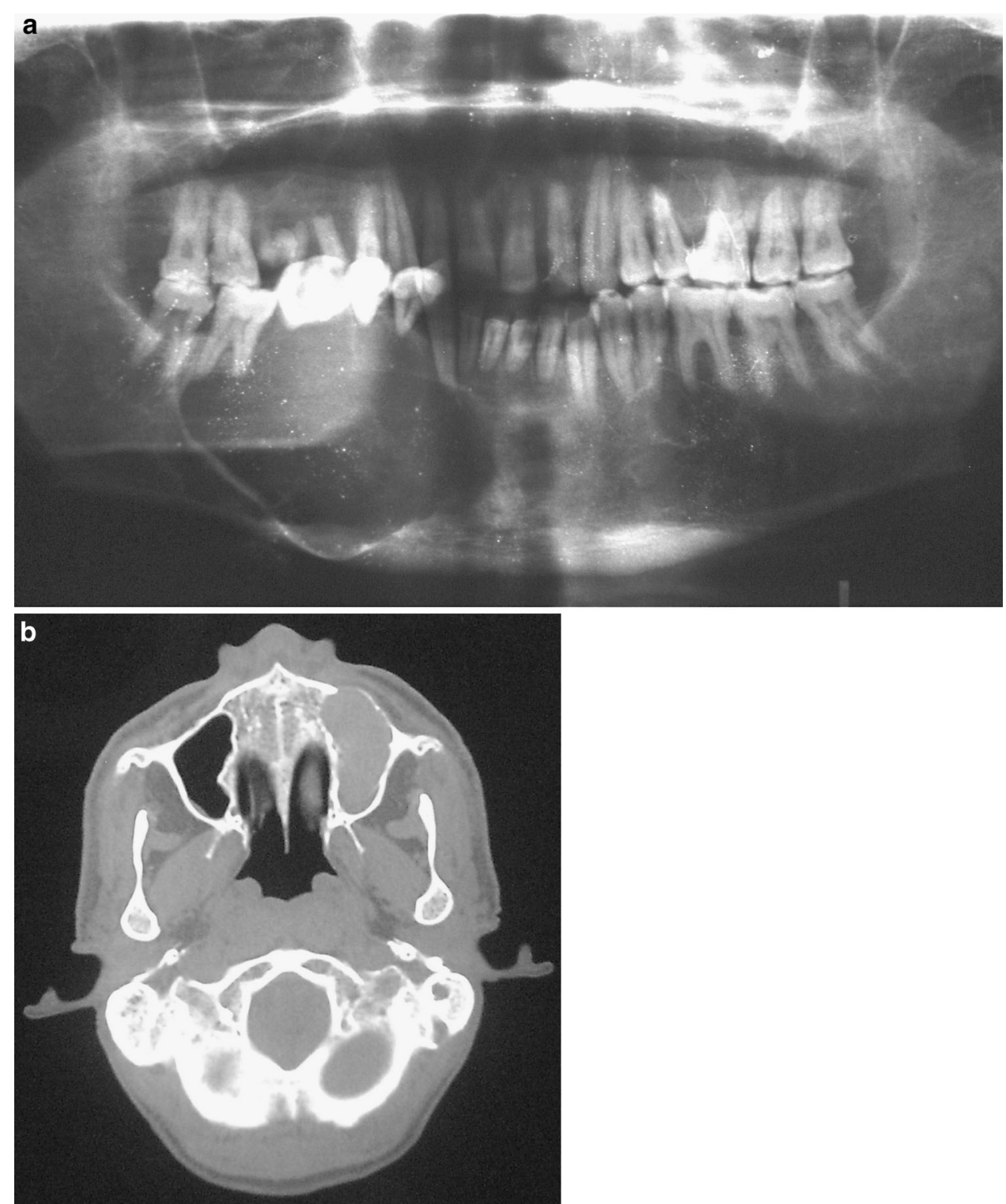

second molar and mesial displacement of canine (Fig. 2a). CT scan was advised to elicit the extent of lesion in the left maxillary sinus region as it was not evident on conventional radiographs. The left maxillary sinus was hyperdense with slight expansion of the anterior wall (Fig. 2b). Coronal section showed the mediolateral extent of the same lesion. CT axial scan showed a heterodense, expansile lesion with well-defined borders in right body of mandible.
There is evidence of lingual cortical plate perforation. Three-dimension CT scan showed the full extent of the lesion (Fig. 3).

Based on clinical presentation and typical radiographic features, a provisional diagnosis of benign fibro-osseous lesion was made. Routine blood investigations including serum calcium and alkaline phosphatase were within normal range. 


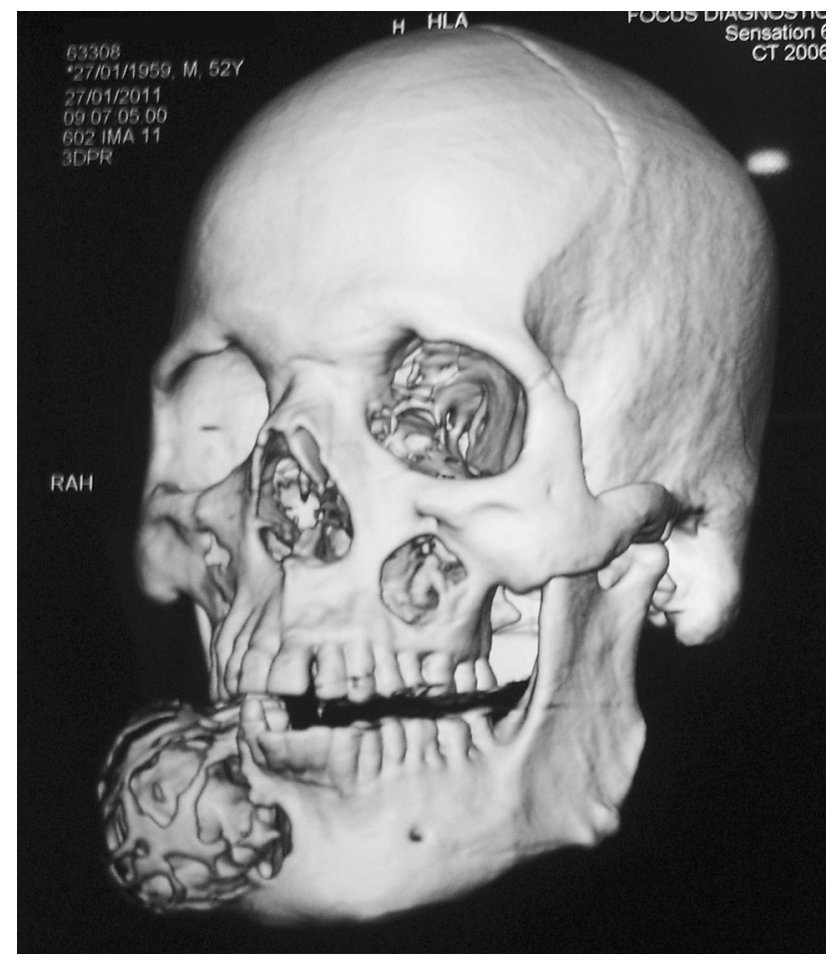

Fig. $33 \mathrm{D}$ reconstruction of the CT image showing extent of the lesion

Fine needle aspiration showed no fluid aspirate. Under local anaesthesia, an incisional biopsy was performed at the most expanded part of the buccal cortex. Histopathological examination was suggestive of COF.

Under general anaesthesia both the lesions were enucleated in toto via an intraoral approach (vestibular incision) along with extraction of the involved teeth (Fig. 4ac). The bony margins were freshened and trimmed and primary closure was achieved.

Post-resection specimen microscopically showed a highly dense connective tissue stroma with thick collagen bundles and numerous endothelial lined blood vessels that were haphazardly arranged with fibroblasts. Few areas showed irregular basophilic calcified masses along with more osteoid tissue; exhibiting osteoblastic rimming and osteocytes in H\&E stained tissue section confirming both the lesions to be cemento-ossifying fibroma (Fig. 5a, b).
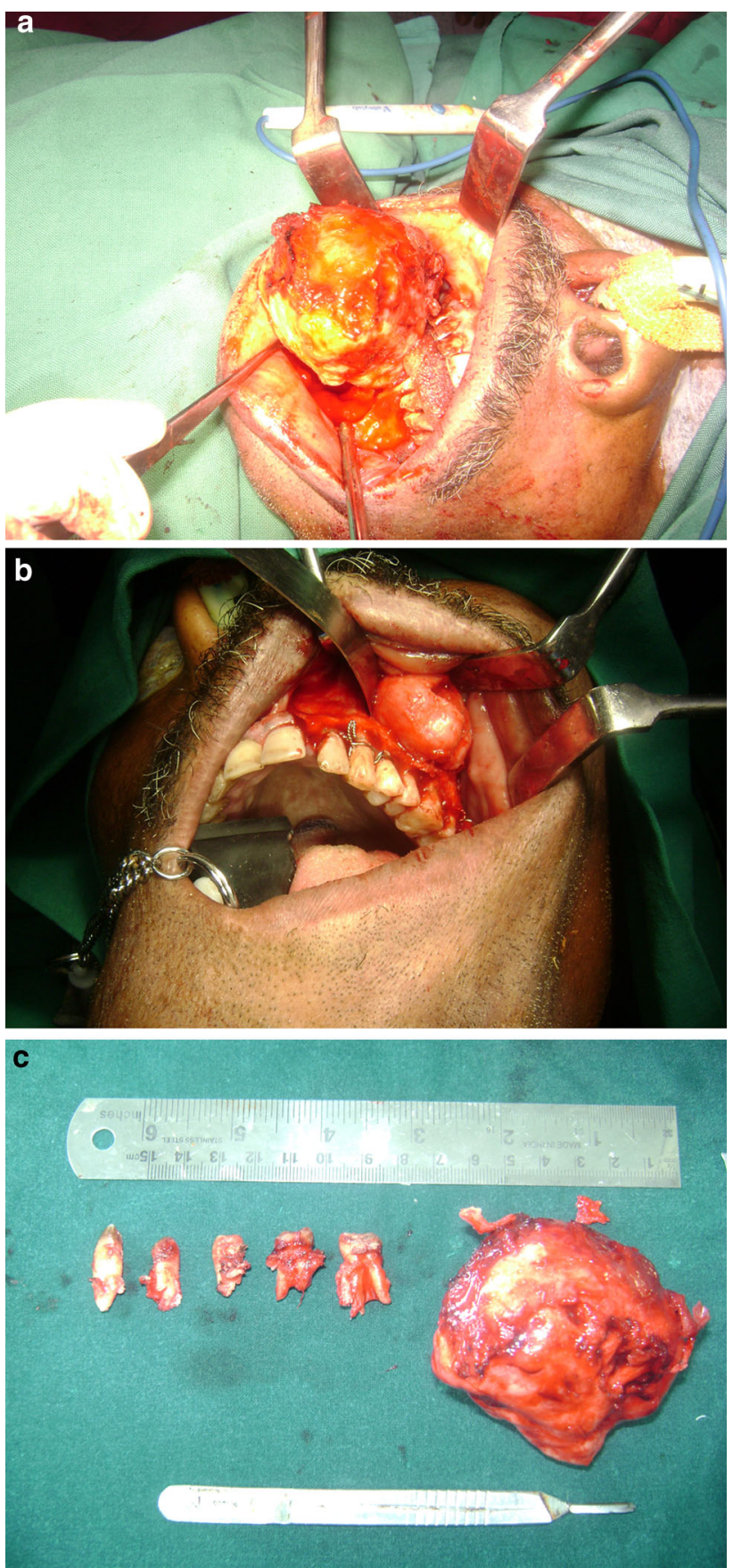

Fig. 4 a Lesion in the right body of the mandible being excised intoto. b Lesion in the left maxillary antrum. c Resected mandibular lesion along with extracted teeth 

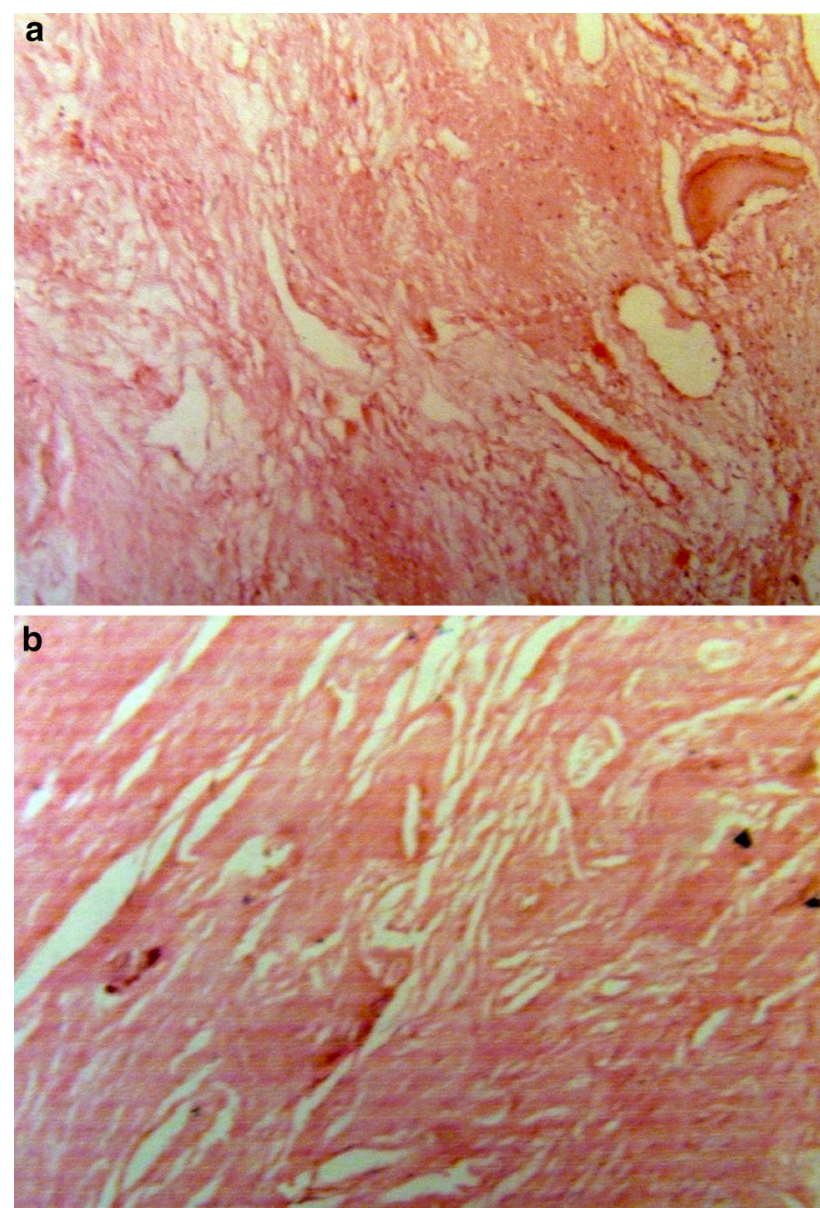

Fig. 5 H\&E stained tissue section of mandibular lesion (a) and antral lesion (b) showing dense connective tissue stroma with thick collagen bundles and numerous endothelial lined blood vessels with haphazardly arranged fibroblasts. Basophilic calcified masses are seen, exhibiting osteoblastic rimming
The patient is under follow-up with no evidence of recurrence (Figs. 6, 7a, b, 8a).

\section{Discussion}

Cemento-ossifying fibroma or ossifying and/or cementifying fibroma has been described as a demarcated or rarely encapsulated neoplasm consisting of fibrous tissue containing varying amounts of mineralized material resembling bone and/or cementum [1]. Menzel in 1872, first described a variant of ossifying fibroma in a 35-year-old woman with a long standing large tumour of the mandible and termed it as COF [15]. COF was considered to be a benign osseous tumor, very closely related to other lesions such as fibrous dysplasia, cementifying periapical dysplasia or cemento-osseous florid dysplasia and was termed "cement-ossifying fibroma". However in the 1992 WHO classification it was considered as a separate entity [2]. Presently, the term ossifying fibroma is recommended for this lesion in the latest WHO classification of odontogenic tumors [2], because the difference between bone and cementum is equivocal [16].

Cemento-ossifying fibroma is also considered to be a central neoplasm of the bone and this controversy due to confusing terminology has resulted in differences of opinion and management of these lesions. Though previously considered as an odontogenic tumor, today it is best classified as an osteogenic neoplasm [17].

The tumor most probably originates from the periodontal membrane and thus is of double embryonic origin (ectodermic and mesodermic). In fact, connective tissue of the periodontal membrane can contemporarily elaborate bone, cementum and fibrous tissue [2, 11, 14].
Fig. 6 Immediate post operative orthopantomograph

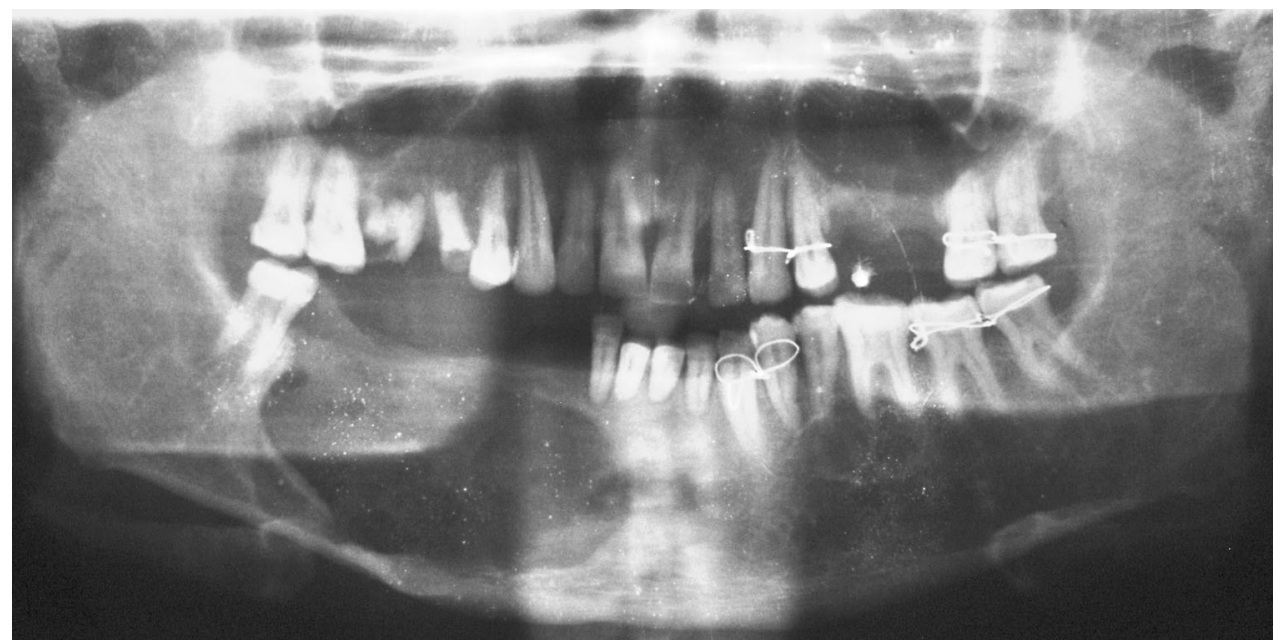



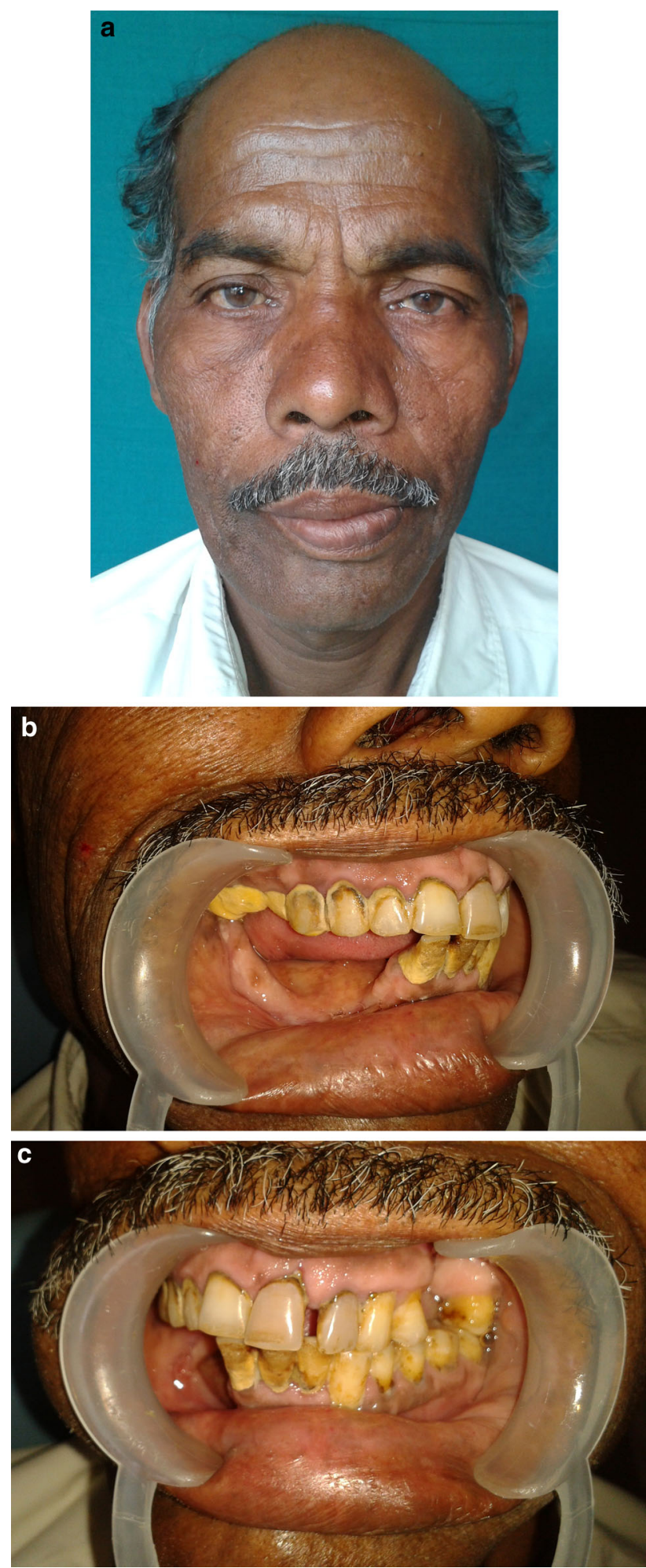

Fig. 7 a One year post-operative photograph in frontal profile. b One year post-operative intra oral photograph showing no evidence of recurrence of the mandibular lesion. c One year post-operative intra oral photograph showing no evidence of recurrence of the maxillary lesion
Bernier hypothesized that the etiopathogenesis of $\mathrm{COF}$ within the jaw bone might be caused by a stimulus (such as tooth extraction) which may activate the production of new tissue from the remaining periodontal membrane. In our patient the stimulus was probably trauma to right lower jaw.

Clinically, these tumours manifest as a well delineated, asymptomatic, slow-growing intra-bony mass that normally cause displacement of tooth as an early clinical feature though over time the lesion may become large enough to cause facial deformation $[12,17,18]$. In our case a similar clinical feature was noticed.

Central COFs are typically well-circumscribed, solitary or multilocular [7] radiolucencies with scattered radioopaque foci [2]. The lesion however can show a number of patterns depending on the degree of mineralization [9, 12]. Radiographically, OPG and CT Revealed a well-defined multilocular radiolucent lesion with sclerotic margins in the mandible and a unilocular lesion in the maxilla.

Cemento-ossifying fibroma is usually composed of cellular fibroblastic tissue containing little or plenty of mineralized tissues-bone (woven and lamellar), cementumlike material, and dystrophic calcification [16]. Post resection specimen of both maxillary and mandibular lesions showed histologically similar features of highly dense connective tissue stroma with thick collagen bundles and numerous endothelial lined blood vessels that were haphazardly arranged with fibroblasts. Few areas showed irregular basophilic calcified masses along with more osteoid tissue; exhibiting osteoblastic rimming and osteocytes in H\&E stained tissue section $[19,20]$ confirming both the lesions to be COF. The histological findings such as well vascularised fibrocellular tissue with the capacity to form immature bony trabeculae and cementoid formations, are not specific of this lesion and can also be seen in fibrous dysplasias. A definitive diagnosis therefore requires correlation of the clinical, radiological and histological findings [12].

The differential diagnosis included fibrous dysplasia, osteoid osteoma, osteoblastoma, chronic sclerosing osteomyelitis, ameloblastoma, squamous cell carcinoma of the maxillary sinus, calcifying epithelial odontogenic tumor (Pindborg tumor) and calcifying odontogenic cyst (Gorlin cyst) $[2,21,22]$.

Recurrence of these benign tumours following surgery is considered rare, although the reported recurrence rate varies between 0 and $30 \%$ [5].

There were no signs of recurrence after 1 year of treatment. Uniqueness of this case is that COF was present in both maxilla and mandible and this is the only such case reported in literature till date. 
Fig. 8 a One year postoperative orthopantomograph showing no recurrence of the mandibular lesion. b One year post-operative PNS view showing no recurrence of the maxillary lesion
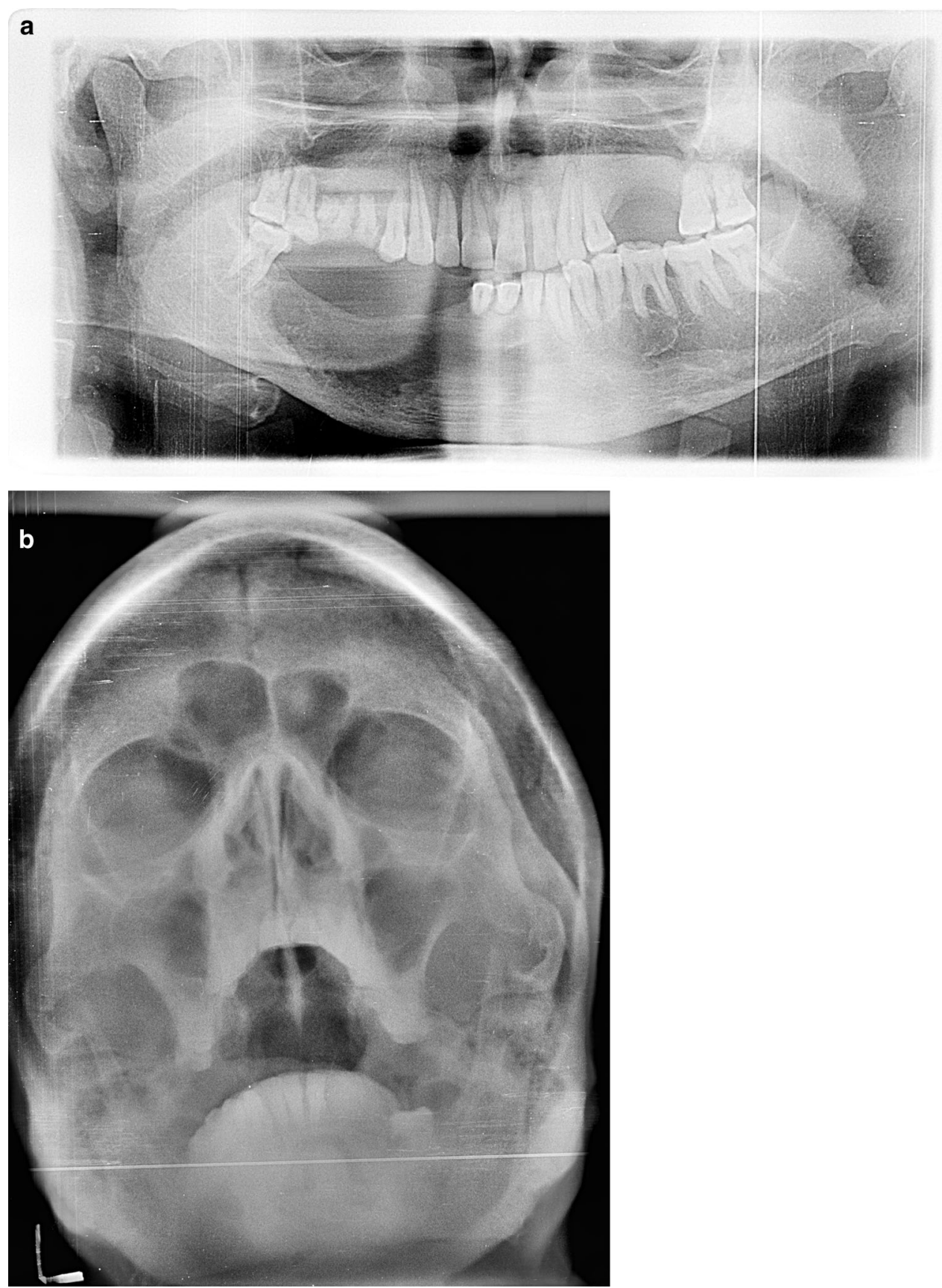

\section{Conflict of interest None.}

\section{References}

1. Dinkar D, Arathi K, Ahmed S, Rai N (2010) Bilateral cemento ossifying fibroma of mandible. IJDA 2:45-47

2. Tamiolakis D, Thomaidis V, Tsamis I (2005) Cemento-ossifying fibroma of the maxilla: a case report. Acta Stomatol Croat 39:319-321

3. Hamner JE, Lightbody PM, Ketcham AS, Swerdlow S, Bethesda (1968) Cemento-ossifying fibroma of the maxilla. Oral Surg Oral Med Oral Pathol 26:579-587
4. Gunaseelan R, Parameswaran A, Erumbala R, Kannan R (2007) Large cemento-ossifying fibroma of the maxilla causing proptosis: a case report. Oral Med Oral Pathol Oral Radiol Endod 104:e21-e25

5. Ertug E, Meral VG, Saysel M (2004) Cemento-ossifying fibroma: a case report. Quintessence Int 35:808-810

6. Takeda Y, Fujioka Y (1987) Multiple cemento-ossifying fibroma. Int J Oral Maxillofac Surg 16:368-371

7. Zupi A, Ruggiero AM, Insabato L, Senghore N, Califano L (2000) Aggressive cemento-ossifying fibroma of the jaws. Oral Onco 36:129-133

8. Jung SL, Choi KH, Park YH, Song HC, Kwon MS (1999) Cemento-ossifying fibroma presenting as a mass of the parapharyngeal and masticator space. Am J Neuroradiol 20:1744-1746 
9. Karunakaran, Rajeshwar, Murugesan (2010) Cemento-ossifying fibroma possibility for malignant transformation? JIADS 1:41-42

10. Trijolet JP, Parmentiera J, Surya F, Gogaa B, Mejeanc N, Laurea B (2011) Cemento-ossifying fibroma of the mandible. Eur Ann Otorhinolaryngol Head Neck Dis 128:30-33

11. Mintz S, Velez I (2007) Central ossifying fibroma: an analysis of 20 cases and review of the literature. Quintessence Int 38:221227

12. Silvestre-Rangil J, Silvestre FJ, Bernal JR (2011) Cementoossifying fibroma of the mandible: presentation of a case and review of the literature. J Clin Exp Dent 3:e66-e69

13. Zhang T, Liu H, Liao G, Liang Y, Chu M, Wan C, Liang L, Zheng G (2010) Detection of Notch signaling molecules in cemento-ossifying fibroma of the jaws. J Oral Pathol Med 39:263-268

14. Jayachandran S, Sachdeva S (2010) Cemento-ossifying fibroma of mandible: report of two cases. J Indian Acad Oral Med Radiol 22(1):53-56

15. Hammer JE, Scofield HH, Cornyn J (1968) Benign fibro-osseous jaw lesions of periodontal membrane origin: an analysis of 249 cases. Cancer 22:861-878
16. Ono A, Tsukamoto G, Nagatsuka H, Yoshihama Y, Rivera RS, Katsurano M, Yao M, Sasaki A (2007) An immunohistochemical evaluation of BMP-2, -4, osteopontin, osteocalcin and PCNA between ossifying fibromas of the jaws and peripheral cementoossifying fibromas on the gingiva. Oral Oncol 43:339-344

17. Prasad BS, Rao K, Swathi D (2010) Cemento-ossifying fibroma-a case report. Ann Essences Dent 2:169-173

18. Terezhalmy GT, Riley CK, Moore WS (2000) Clinical images in oral medicine and maxillofacial radiology-fibrous dysplasia. Quintessence Int 31(10):768-769

19. Keefe MA, Martín-Granizo R, Sanchez-Cuellar A, Falahat F (2000) Cemento-ossifying fibroma of the upper gingivae. Otolaryngol Head Neck Surg 122(5):775

20. Hall EH, Naylor GD, Mohr RW, Warnock GR (1987) Early aggressive cemento-ossifying fibroma: a diagnostic and treatment dilemma. Oral Surg Oral Med Oral Pathol 63:132-136

21. Sarwar HG, Jindal MK, Ahmad S (2010) A case report of cemento-ossifying fibroma. J Maxillofac Oral Surg 9(2):178-181

22. Passos M, Azevedo R, Janini ME, Maia LC (2007) Peripheral cemento-ossifying fibroma in a child: a case report. J Clin Pediatr Dent 32:57-60 